\title{
The influence of Chinese context on attrition of English tense
}

\author{
Huan Deng \\ School of Foreign Languages, Wuhan Media and Communications College of Huazhong Normal University, \\ Wuhan, Hubei, China
}

\begin{abstract}
From psycholinguistic aspect, language learning not only requires acquisition and progression, but it also exists in attrition and regression. Within Chinese as a native language, the learning and living environment would directly affect the language input and contact for English as a foreign language (EFL) learner. English tense is totally different from that of Chinese in terms of concept. Based on Inverse Hypothesis, the present thesis aims to take English tense as a breakthrough point in this diachronic research, as well as to reveal and analyze the variability of mastering tenses for EFL learners. Meanwhile, it also strives to validate the feasibility of slowing down the speed of language attrition by increasing the English input and contact. In Chinese context, how to resist attrition effectively and retain their acquired language abilities will yield a lot of benefits to language teaching and learning both for teachers and EFL learners.
\end{abstract}

Keywords: language attrition; tense; Chinese context; English learning

\section{LANGUAGE ATTRITION}

Language attrition wasn't defined as a brand-new linguistic field until the inaugural conference was held at the University of Pennsylvania in 1980. Language attrition refers that the abilities of bilingual or multilingual learners to speak and understand a certain language are weaken within time due to cease or reduction of use. (Ni Chuanbin, 2006). According to the categories of the target language and the language environment of attrition, language attrition can be classified into four types: (1) Foreign language attrition in native language environment; (2) Foreign language attrition in foreign language environment; (3) Native language attrition in foreign environment; (4) Native language attrition in Native language environment (Kopke \& Schmid 2003). In native language environment, there are a lot of factors which can affect foreign language attrition. Ni Chuanbin (2012) has already put forward seven important factors through his empirical research, namely, language proficiency level prior to attrition, time onset of attrition, exposure of the language attrited, age at the onset of language attrition, foreign language instruction, social affective factors, and literacy. Those researches on factors of affecting foreign language attrition can provide new implications for foreign language teaching and study- ing, which could accelerate the promotion for language education.

In the 1990s, Canadian linguist Vechter (1990) has proposed Inverse Hypothesis through a series of empirical works. This hypothesis can simply be explained by "the higher the degree of attainment, the lower the degree of attrition". It illustrates the negative correlation between the degree of foreign language attrition and EFL learners' language proficiency level prior to attrition and exposure quantity: the higher language proficiency level prior to attrition a EFL learner attains, the rarer frequency the language attrition would arise in, vice versa; the more exposure of the target language a EFL learner brings out, the lower amount the language attrition would reach to, vice versa. Language attrition is the mirror of its acquisition. In other words, in the process of language acquisition, the distinction between native and foreign language is related to the degree of language attrition. This hypothesis reveals the mutual influences between native and foreign language and brings a fresh and reversed angle of view as a powerful force to improve the efficiency of language acquisition.

In recent ten years, more and more scholars in China have begun to put their efforts in EFL attrition in Chinese context. They have already introduced a great number of theories on language attrition back from 
abroad, which lay more emphasis on language attrition in native language environment. Only theory studying isn't enough at all. Some researchers have moved their focuses to empirical studies on English vocabulary, which maintain a high frequency of language attrition. Compared with the amount of studies on English vocabulary, the amount of studies on English grammar is relatively insufficient, not to mention the focus in English tense. In this case, this paper is such a valuable achievement to explore the attrition in English tense in Chinese context.

However, English and Chinese belong to different language systems, which cause great difficulties in English acquisition in Chinese context. There is a huge gap between the formation of English tense and Chinese tense. Hence the great differences would make the learning of English tense more and more difficult. In most cases, Chinese tense could give a negative influence on the application of English tense. In Chinese context, more and more Chinese will squeeze into the time for English learning so the attrition of English grammar would occur in English acquisition. So the deterioration of the acquired English grammar proficiency can be due to the attrition by Chinese context.

Taking English tense as a point of view, the present thesis is based on Inverse Hypothesis in order to promote the core research: through practical experiment, collect sufficient evidence and prove out the correct and effective methods to help those EFL learners to retain their acquired English proficiency by resisting language attrition.

\section{RESEARCH METHOD}

\subsection{Participants}

There are 3 groups of college students in this research: Group 1 includes 30 non-English majors in Grade 2; Group 2 includes 30 English majors in Grade 2; Group 3 includes 30 English majors in Grade 4. The English scores of all the participants in College Entrance Examination is over 90 points besides $92 \%$ scores lying between 90-100 points (total points are 150). The English curriculum for non-English majors is 4 periods per week from the first semester to the fourth semester. The last year for students in Grade 4 contains two parts: 2 or 3 major courses and thesis writing in the seventh semester; graduation practice in the eighth semester without any courses.

\subsection{Questionnaires}

A questionnaire will be involved in this research before the specific test paper on English tense. The Questionnaire is made up of two parts. In each part, there are several question designed to search infor- mation from the participants. These two parts are as following:

1) Present situation of English learning: this part is mainly about the subjects' English learning habits, including subjects' interest and attitude towards English learning; acceptance of full English teaching; the amount time spent in English learning every day.

2) Present situation of learning English grammar: this part is more concerned about the subjects' personal experience of grammar learning, including: attention degree of grammar learning; the methods or approaches for grammar learning outside class; their own difficult learning points in grammar; self-evaluation on their mastery degree of English tense.

The instruction of the questionnaire will make a clear explanation to the subjects that this is just a study for collecting research information and irrelevant to their summative evaluation of English learning So the subjects need not to write their names on the paper but they should finish every single question by their own experience and make every decision without any help from others in order to obtain the true data for analysis.

All the participants in those three groups in the specific test should be involved in the questionnaire. Another 100 pieces of questionnaires will be distributed at random to different students in different majors and grades. Accordingly, there would be 190 questionnaires distributed.

\subsection{Testing paper design}

The testing design is the most important part of the research. A good test paper will contribute a lot to the success of data collection and reach the achievement of the research.

There are 16 types of English tenses, but only 10 of them are basic forms in our daily use. These 10 types are based on tenses and aspects, namely, present tense, past tense, future time, present progressive aspect, past progressive aspect, future progressive aspect, present perfective aspect, past perfective aspect, present perfective progressive aspect, and past perfective progressive aspect. In order to obtain typical and effective data, when the testing paper is designed, 2 tenses (past and present) and 2 aspects (progressive and perfective) are mainly observed.

The concept of English tense shares the similar applied context with Chinese tense while the concept of English aspect differs from Chinese tense in formation and connotation. According to these dissimilarities, two set of testing paper are designed, each of which contains 25 multiple choice questions and 25 blank-filling questions. Each question is scored by 2 points, totally 100 points for each set of testing paper. The grammar points of each question in two sets are consistently matched with each other. In addition, the 
degrees of difficulty for two sets of paper are equivalent to each other within the limit of $50 \%$ repetition rate. When designing the stems, we would try our test to trim uncommon words or words beyond students' normal mastery degree of vocabulary so that the self-consciousness and capability of tense could be comprehensively demonstrated and analysed by the testing paper. Therefore, the reliability of testing paper is reasonable and convincing.

The first test is arranged at the beginning of the semester and the second one will be finished by the end of the academic year. Each test would last for 60 minutes. The grammar teaching during these two tests should be carried out as normal without any extra explanations and exercises on English tense.

\section{RESULTS AND DISCUSSION}

\subsection{Analysis on questionnaires}

Out of 190 questionnaires, 188 were returned with 12 non-effective papers. Thus far, 176 questionnaires are successfully collect for analysis.

According to the data analysis on questionnaires, there are several important results we need to pay attention to.

Firstly, both the English majors and non-English majors have fully realized the importance of grammar learning without huge differences between them. All the participants have shown their lack of confidence in grammar capability, especially those non- English majors who attribute English learning without any improvement to the poor foundation of grammar.

Secondly, the most difficult language points of English grammar chosen by all the participants are subordinated clauses, tense and subjective mood. However, in China, all the basic language points of grammar have been taught in senior high school. The grammar teaching in college is just a supplement or improvement to that of high school. Owing to this teaching status, the fact lies in that there isn't a fixed teaching section for grammar in college. In fact, each student's grammar level differs a lot. The poorer foundation students begin with in college, the less confidence they could gain when studying English grammar. All these above make grammar attrition more obvious day by day.

Thirdly, compared with non-English majors, English majors are more willing to accept full-English teaching which could assist them to increase their English input. $83 \%$ of English majors could spend more than 2 hours (less than 2.5 hours) a day on English learning after class while the span for $92 \%$ non-English majors could only keep in less than 1 hour a day. 95\% courses in curriculum for English majors are directly related to English. English majors have a large contact with English in the process of teaching and learning. However, for non-English ma- jors, there only exist 4 periods of English a week within 4 semesters in the 4-year studying in college. Meanwhile such limited time for English learning should comprise of 5 elements: listening, speaking, reading, writing and translation. All the other courses for non-English majors are taught in Chinese so as to make English input and contact less and less. According to the amount of English input and contact, there is a gap between English majors and non-English majors. So how to bridge the gap to weaken the attrition is of great significance.

\subsection{Analysis on results between groups}

Table 1. Testing results for the attrition of English tense in Chinese context

\begin{tabular}{lllll}
\hline Participants & Testing & Number & Mean & Std. Deviation \\
\hline Group 1 & Test 1 & 30 & 67.9 & 8.2 \\
& Test 2 & 30 & 68.5 & 7.5 \\
Group 2 & Test 1 & 30 & 79.9 & 6.5 \\
& Test 2 & 30 & 83.1 & 4.9 \\
Group 3 & Test 1 & 30 & 85.4 & 5.0 \\
& Test 2 & 30 & 85.1 & 5.1 \\
\hline
\end{tabular}

As it is shown in Table 1, there is a cross-sectional comparison among the testing results of 3 groups. The average scores of Group 1 in 2 tests are both much less than those of Group 2 and Group 3. The testing stability of Group 1 is also not as good as the other groups. According to the data analysis, in Chinese context, the mastery degree of English tense for non-English majors is apparently lower than those of English majors. Compared with the average score of Test 1 in Group 1, that of Test 2 is only a little bit higher although the students in Group 1 has already gone through another two semesters of English learning between these two tests.

The students in Group 2 and 3 are all English majors. Although they share the same living and studying environment with the students in Group 1 in Chinese context, their English input and contact are obviously increasing day by day than those of non-English majors in Group 1. So the students in Group 2 and 3 have a good command of English tense with much less attrition.

According to the longitudinal comparison between Group 2 and Group 3, although the average scores of Group 3 are both higher than that of Group 2, which is consistent with the truth that the students in Group 3 have already learnt four-year major English, the students in Group 2 have an obvious improvement on the mastery degree of English tenses. But there is one decline in Group 3 we need to pay more attention to. The second average score of Group 3 drops a bit (only 0.3 less) than the first one. Outwardly, the students in Group 3 have a better command of English tense, but when they come to their fourth year as graduates, especially in the eighth semester, most of them would go out of college into their internship without much 
devotion into English studying, the decline of English input and contact would lead to less improvement and more attrition. Moreover, during two semesters' English immersion, the huge progress made by Group 2 has validated the feasibility of much improvement with less attrition.

To sum up, English input and contact have multiple influences on attrition of English grammar. In Chinese context, the amount of English contact is decided by the frequency of using Chinese. In order to keep the amount of English contact, the EFL learners should overcome the influence of their native language by reducing the frequently-used Chinese voluntarily and self-consciously, especially when learning English in class. The growth in English input and contact will reinforce the difficult grammatical points effectively as well as to weaken the effect of language attrition.

\subsection{Analysis on results in English tense}

Table 2. Testing results for different attrition between tenses and aspects

\begin{tabular}{llll}
\hline Participants & Testing & Mean (tenses) & Mean (aspects) \\
\hline Group 1 & Test 1 & 13.7 & 11.1 \\
& Test 2 & 13.2 & 10 \\
Group 2 & Test 1 & 16.4 & 16 \\
& Test 2 & 16.9 & 16.1 \\
Group 3 & Test 1 & 17.1 & 16.8 \\
& Test 2 & 17.4 & 16 \\
\hline
\end{tabular}

Test 1 and Test 2 share $40 \%$ repetition, including 10 questions (20 points) about two tenses and 10 questions (20 points) about two aspects.

As it is shown in Table 2, only in Group 2, both two average scores in Test 2 are higher and those in Test 1. Based on the studying experience of students in Group 2 mentioned before, their immersion of English for two semesters has put a great effect on reducing the attrition on tenses and aspects. Compared with the average scores of tenses, the average scores of aspects in both Group 1 and Group 3 have decreased, especially in Group 1. The possibility may lie in that the application of English aspects is much difficult than that of tenses so the attrition in aspect are easy to occur than that in tenses in learning.

Chinese tenses are consistent with English tenses in terms of concept, both including past time, present time, and future time. So it is easier for students to understand the connotation of English tenses. While the concept and formations of English aspects are different from those of Chinese. In Chinese, different words are added into a sentence to express the progressive and perfective concepts. But in English, the directivity of aspects is sometimes confused with Chinese and difficult to figure out the tiny differences. Meanwhile, the transformation of English tenses is mainly achieved by the variable forms of verbs, but the formation of English aspects not only needs the variable forms of verbs but also contains the usage of auxiliary verbs such be or have. So the master of aspects is more complicated than tenses, which causes much more attrition of aspects.

All in all, Chinese context gives some impact of mastering and applying English tenses and aspects. When English input and contact are reduced even ceased, even though the participants attain a high prior proficiency level, the attrition would be easier to occur. So the stability of English input and contact keeps effective resistance of attrition on English tense.

\section{CONCLUSION AND SUGGESTIONS}

\subsection{Conclusion}

This paper is a preliminary investigation of the influence of Chinese context on attrition of English tense for EFL learners. Based on the previous analysis, the following major findings can be achieved.

Firstly, In Chinese context, there lies in a negative correlation between the degree of language attrition and the amount of English input and contact. The more English input and contact, the less attrition that would occur in grammar learning. So if EFL learners reduce the amount of English input even stop learning English, their English proficiency level would become retrograde due to language attrition. Contrarily, if they keep devoting themselves in English learning with sufficient amount of English input, it is much more difficult for grammar attrition to arise.

Secondly, in the terms of attrition extent, there exist great differences between English tenses and aspects. EFL learners pay more attention to learn the formation and application of aspects because of their high difficulty. Once they reduce or stop learning English, the attrition of aspect would emerge more noticeably than that of tenses.

So in order to resist grammar attrition, we should first make great efforts to improve students' prior proficiency level and emphasize more on the grammatical points such as tense which lead more confusion with Chinese grammar. Equally we also grasp those difficult and unique grammar points such as subjective mood in order to slow down the speed of its language attrition.

However, there are still several weaknesses in the present research. So to make a brief conclusion on the limitations would help to make a better research next time. Firstly, this research had only referred to some questionnaires and testing paper. So the validity of those testing paper needs to be furthered confirmed. Secondly, not all the English tenses are involved in the test. So the results of tests maybe couldn't demonstrate the overall status of tense attrition. Lastly, as it is mentioned above, there are at least 7 factors which can affect foreign language attrition. But in this paper, we focus more on the exposure or contact to the target language and English input. The other factors are also 
related to language attrition and need to be considered into tests. To sum up, further experiments and investigations should be carefully taken in order to gain more convincing and significant findings.

\subsection{Suggestions}

According to those major findings above, there are four suggestions for improvement of teaching and learning.

Firstly, adjust the curriculum of college English in order to increase the amount of English input and contact. In Chinese context, non-English majors obtain such a limited amount of exposure to English as well as uneven foundations of English grammar. Once they stop learning English, their language attrition would be easier to come out to ruin their English ability. English grammar and regulations are more likely to be confused by Chinese thinking and mixed with Chinese grammar. It is more likely for language attrition to exhibit its effect. According to the practical command of EFL learners in their first year of college, a fixed grammar course should be arranged in order to compensate students' weaknesses in grammar until their grammatical proficiency level reach the standard. At the same time, it is necessary to extend the college English course into the third year even the fourth year in order to keep students' English input and contact sufficient. Less attrition in grammar before graduation would help EFL learners a lot in applying for jobs.

Secondly, improve the traditional teaching mode of grammar. Grammar is an invisible link to connect listening, speaking, reading, writing and translation as a union for English learning. Its application lies in every area of English studying. So grammar teaching cannot be separated or ignored by other teaching sections. Taking advantage of cognitive assimilation, teachers should intermingle grammar teaching of every language point into other sections to reinforce the basic points in grammar. Simple repetition of grammar interpretation in high school couldn't help college students to rebuild a new grammatical system, which is the first and vital task for college English teachers to undertake (Huan Deng, 2011). Teachers' mission in class is not to teach grammar but to interpret the usage of grammar in communication. Moreover, an active and easy class atmosphere is also of great importance. Teachers should make full use of diverse teaching tools such multi-media instruments to stimulate students' motivations. Furthermore, the learning process would become easier to be absorbed.

Thirdly, enrich extracurricular activities with English to fully motivate students' initiative of English learning. The more time spent in English, the lower speed the language attrition would occur with. For most non-English majors, English class is probably the only and best place to increase their English input. The high efficiency in college English class gives a positive reinforcement to grammar. Nevertheless, after class, Chinese thinking habit would interfere with the original thinking model of English grammar. Consequently, teachers should help students to create more chances of using English. The traditional methods such as homework or exercises are also necessary. But what seem more eager for students to participate in are interesting and colourful activities related to English, such as English corner, all kinds of English competitions. Other activities after class could not only help EFL learners to keep the amount of English input and contact, but also build up their confidence in learning English.

Last but not the least, keep the lines of communication with students open and relieve students' anxiety in grammar learning. In traditional grammar class, teachers are lecturing more while students are just sitting and listening. In this case, students are lack of sense of participation and independent learning. The famous Russian educationist Sukhomlinski once said: "Let students experience the participation of learning knowledge by themselves. Only this kind of emotive devotion could be considered as a vital prerequisite to call their interests in knowledge." So teachers and students should work together to build up a free platform for communication with each other and break through the traditional teaching model of teacher-oriented classroom. Furthermore teachers should also give more space to students for thinking freely in order to reconstruct a new grammar system. In that sense, teachers and student can achieve two-way communication which makes teaching benefits teachers as well as students.

All in all, with the development of deepening globalization day by day, English, as an international language, shares the strong responsibility of practical communication. Grammar, as an important element of English, is the escort for EFL learners to fully improve their language skills. In Chinese context, the approach to resist or relieve the grammar attrition could give EFL learners a lot of beneficial supports on efficient English learning.

\section{ACKNOWLEDGEMENT}

This paper is sponsored by Key Program of Hubei Education and Science Foundation during the $12^{\text {th }}$ Five-Year Plan Period (GN: 2014A140).

\section{REFERENCES}

[1] Chuanbin, Ni. 2006. Analysis on factors affecting foreign language attrition. Foreign Language Teaching and Reacher, 38(1).

[2] Kopke, B \& M.S. Schmid. 2003. Language attrition: the next phase. In M.S. Schimid, B Kopke, M. Keijser, \& L. Weilemar (eds). Proceedings of the International Conference on First Language Attrition: Interdisciplinary 
Perspectives on Methodological Issues. Amsterdam: John Benjamins.

[3] Chuanbin, Ni. 2012. Research on factors affecting foreign language attrition. Beijing: World Publishing Corporation.

[4] Vechter, A.S. Lapkin \& V. Argue. 1990. Second Language retention: A summary of the issues. The Canadian Modern Language Review, 46 (2).

[5] Huan, Deng. 2011. Research on teaching notions and mode innovation of foreign language: Analysis on English grammar teaching in independent colleges from educational psychology. Wuhan University Press.

[6] Ellis, R. 2000. Understanding Second Language Acquisition. Shanghai: Shanghai Foreign Langue Education Press.
[7] Alex, H. 2002. The L2 Acquisition of tense---Aspect Morphology: The development of Tense---Aspect in English as a second language and the variable influence of inherent aspect. J. Benjamins Pub.

[8] M.A.K. Haliday. 2000. An Introduction to Functional Grammar. Foreign Language Teaching and Research Press.

[9] Zhonggen Yu. 2010. Attrition in the English Language among EFL Tertiary Students in China. Nanjing: Southeast University Press.

[10] Kopke, B. 2004. Neurolinguistic aspects of attrition. Journal of Neurolinguistics, 17. 